\title{
El paradigma del bURgués INDiANo en LA LOCA DE LA CASA, DE GALDós
}

\author{
Francisco J. Quevedo García \\ Universidad de Las Palmas de Gran Canaria
}

\section{RESUMEN:}

El personaje del indiano en el siglo XIX es representativo de una sociedad española con notables problemas económicos que impulsa a la emigración, así como de una imagen mítica de América como tierra de oportunidades. En este caso, trabajamos la figura de José María Cruz, en La loca de la casa, a través del cual apreciamos la apuesta galdosiana por el trabajo de la burguesía activa, necesario para la regeneración española, pero sin caer en el exceso del materialismo con el culto absoluto al dinero.

PALABRAS CLAVE:

Indiano, América, Galdós, burguesía.

\begin{abstract}
:
The character of the indiano in the nineteenth century is representative of a Spanish society with notable economic problems, which drives emigration, as well as a mythical image of America as a land of opportunity. In this case, we work on the figure of José María Cruz, in La loca de la casa, through which we appreciate the Galdosian commitment to the work of the active bourgeoisie, necessary for Spanish regeneration, but without falling into the excess of materialism with the absolute cult of money.
\end{abstract}

KEYWORDS:

Indiano, America, Galdós, bourgeoisie.

\section{En cuanto al mito de América, el indiano y Galdós}

La historia atestigua que fue en la localidad granadina de Santa Fe donde se suscriben las capitulaciones que son el contrato base de la empresa que llevó al almirante Colón a arribar a la costa de Guanahani en su primer viaje. Es importante entender que ya desde antes de llegar a lo que luego se denominaría América - es decir, antes de que ya tuviera existencia real en el pensamiento español y europeo- ya se estableció un reparto que partía de un proyecto basado en argumentos científicos, pero que se lleva a cabo por la fuerte convicción de Colón en sus posibilidades y que, en cualquier caso, está imbuido de una formulación quimérica. Así, pues, ya antes de arribar a sus tierras América fue deseada como un lugar cuasi mítico, que condensaba 
las aspiraciones de todas las clases sociales, desde la monarquía que creyó encontrar en aquellos lares la mina inacabable que financiara todas sus empresas, hasta los más pobres de sus vasallos que se permitían pensar en fortunas inalcanzables en su lugar de origen. Todo mito contiene un pedazo de verdad, aunque sea un hilo fino, y América se construyó hilvanando muchos hilos en la conciencia europea, y más aún en la española que, no en vano, capitaneaba la aventura. No es de extrañar el surgimiento del mito de El Dorado, que calentó las cabezas de muchos hasta fomentar exploraciones en su busca, como la de Pedro de Ursúa, en la que cobró dimensión literaria el personaje de Lope de Aguirre. Ramón J. Sender lo inmortalizó en La aventura equinoccial de Lope de Aguirre: «No pienso que haya cosas muy nombradas, digo entre las que me acaecieron, sino que todas las horas del día oía hablar de las Indias y de las tierras descubiertas en el nuevo mundo. Se hablaba de eso en Oñate por los muchos navegantes que iban y venían diciendo historias más o menos puestas en razón, que recordaban a veces las de los libros de Amadís» (1976: 25).

Aunque el personaje alcanzara una dimensión especial por razón de sus atrevidas experiencias que le valieron el apodo de El Loco, remiten estas líneas a una imagen cotidiana de su época, en la que el sonsonete de las Indias sonaba por doquier, advirtiéndose que las historias que nacían desde ese territorio parecían tan fantásticas y prometedoras como las del mismísimo Amadís. Como era de esperar, con el paso del tiempo la realidad fue colocando las cosas en su sitio y modelando ese componente mítico, aunque para los españoles, y para los europeos en general, continuó siendo una tierra de promisión. El siglo XIX no fue ajeno a los procesos migratorios hacia América — «Desde los primeros momentos de la independencia, los gobiernos de las nuevas repúblicas latinoamericanas comprendieron que su futuro dependía de la inmigración extranjera. Por esta razón, durante el siglo XIX la mayoría de países latinoamericanos aprobaron leyes y medidas para fomentar la inmigración» ${ }^{1}$. Se estima en cuatro millones los emigrantes españoles a América solo en el periodo comprendido entre las dos últimas décadas del siglo XIX y las tres primeras del siglo XX; en torno a cincuenta años se desplazaron más de un tercio de la población española si atendemos a la cifra del censo de 1897 que ofrece el Instituto Nacional de Estadística sobre la población de derecho: 18268942 millones de españoles. Si en la Península Ibérica esta emigración hacia América se extendió de modo generalizado, en las Islas Canarias, donde nace Benito Pérez Galdós (Las Palmas de Gran Canaria, 10 de mayo de 1843), esa emigración se convierte, más que en coyuntural, en secular. Sería ciertamente exagerado llevar ese proceso migratorio hasta el primer viaje de Colón, puesto que el almirante recaló en el archipiélago antes de partir hacia el mito, pero es indudable que Canarias, ya desde aquellas fechas, se constituye en un centro

${ }^{1}$ M. Ángeles Sallé Alonso (coord.), La Emigración Española en América: Historias y Lecciones para el Futuro, Madrid, Fundación Directa. Ministerio de Trabajo e Inmigración, 2009, pág. 12. 
de parada y fonda en el Atlántico tanto para los que viajan hacía América como para los que regresaban a Europa. Las relaciones entre Canarias y América construyeron un imaginario puente cultural y anímico que se percibió como una vía de escape formal a las penurias económicas de los isleños. Es más que un tópico referirnos a los trasvases que se generan entre Canarias y América, es una seña de identidad insular que pone de manifiesto la construcción de un imaginario atlántico que da carácter propio a este archipiélago. Francisco Morales Padrón subraya: «La singular relación Canarias-América es algo que no cesa de estudiarse porque, precisamente, los lazos persisten en el consiguiente trasvase humano. Fue una corriente de uno a otro lado, que se mantiene viva y dando frutos con una fenomenología particular hoy como antaño» ${ }^{2}$. Y sin recurrir a la autoridad académica, en la calle la tradición muestra ese nexo canario-americano en multitud de manifestaciones que van desde el habla insular hasta coplas como esta: «De Canarias somos / de La Habana venimos / no hace un cuarto de hora / que de allí salimos». No es de extrañar, pues, la presencia de América en la obra galdosiana. Carlos García Barrón sobre el particular precisa la aparición del tema americano en todas las etapas galdosianas:

De hecho, América está presente en la obra galdosiana desde el primer momento. Si nos ceñimos a las tres etapas fundamentales en la evolución de su producción literaria, es decir, la naturalista, la de confrontación de materia y espíritu y la extratemporal, veremos que el interés de Galdós por lo americano corresponde a estas tres fases. En la primera don Benito concibe América como parte de la realidad social española. En Gloria nos encontramos con la fortuna de los Lantigua, fortuna procedente de México. Otro caso es el de don Teodoro Golfín, «famoso sabio que ha corrido toda América haciendo maravillosas curas». Así pues, en esta etapa inicial América se asocia a la aventura, al dinero y en menor grado a la ciencia y al progreso. Más adelante, en las novelas de corte realista y naturalista, la visión de América tiende a centrarse en Cuba. A esta isla, parte del Estado español, van a parar los señoritos arruinados con deseos de rehacer su fortuna. La familia de León Roch nos proporciona a Federico Cimarra, ejemplo de este tipo de personaje. Hay, claro, muchos otros casos como por ejemplo el de José María, amante de Eloísa en Lo prohibido, o Pedro Minio en La de Bringas, o don Evaristo Feijoo, el protector de Fortunata. En América el español puede abrirse paso, hacerse rico y volver a España como el indiano afortunado. ${ }^{3}$

\footnotetext{
${ }^{2}$ Francisco Morales Padrón, Canarias y América, Las Palmas de Gran Canaria, Mancomunidad de Cabildos, Plan Cultural y Museo Canario, 1982, pág. 9

${ }^{3}$ Carlos García Barrón, «América en Galdós», Anales de Literatura Española, n. 5, 1986-1987, pág. 146.
} 
No es cierto, ni mucho menos, que todos los emigrantes a América regresaran ricos a España, pero queda grabada en la conciencia social española, y así lo avala la configuración real y literaria del indiano, esa impronta mítica del nuevo continente. Galdós da cabida, como no podía ser menos dada su observancia a la máxima de retratar con fidelidad su mundo circundante, a la presencia en su novelística de este peculiar emigrante. En su Introducción a una Sociología de la novela española del siglo XIX, José Ignacio Ferreras reparaba en América como asunto literario para los novelistas decimonónicos: «Para el novelista realista del XIX, América constituía la alejada pero obligada referencia del indiano, personaje novelesco generalmente secundario de la obra, o del americano rico al que se solía satirizar» (1973: 255). Y Ángel del Río, en sus Estudios galdosianos, recalaba también en el indiano en la producción del novelista: «[...] el tema de América se presenta como la tierra de un hombre nuevo; el emigrante o indiano, de personalidad vigorosa, capaz de crearse su propio destino y de influir en el destino de los demás, posible agente de renovación en una sociedad desvitalizada como la española» (1969: 125). En la propia familia Pérez Galdós se vivió el asunto de la emigración y del mestizaje americano en primera persona, como era común en el resto de las familias isleñas. José Pérez Vidal, en Canarias en Galdós, da cuenta de esa estrecha relación familiar con América:

De Galdós se ha dicho, sin contradicción, que fue el primero de nuestros grandes novelistas contemporáneos que dio entrada al Nuevo Mundo en sus narraciones. No se ha explicado, sin embargo, el porqué de esa anticipación. Y no ha sido raro, porque el hecho ha sido estudiado principalmente desde América y la explicación había que darla, por el contrario, desde Canarias.

El Archipiélago, situado entre Europa y América, y con una constante deficiencia de medios económicos, ha considerado siempre las tierras americanas como natural campo de expansión. En las épocas de gran depresión principalmente, ha sido rara la familia canaria sin algún miembro en Cuba o en Venezuela. Los problemas americanos han sido para los isleños problemas en gran medida familiares; se les ha sentido, del modo más vivo, en la propia carne. Y en muchos casos los vínculos de sangre han religado de modo definitivo estas relaciones ya tan entrañables. La familia de Pérez Galdós, como se verá, no constituyó en este aspecto ninguna excepción. Bastará anticipar aquí que dos hermanos de Pérez Galdós casaron en Cuba con dos cubanas: Domingo, con Magdalena Hurtado de Mendoza y Tate; Ignacio, con María de la Caridad de Ciria y Vinent. Y que más tarde su hermana Carmen contrajo matrimonio con José Hurtado de Mendoza, hermano de Magdalena. Y lo más interesante: muerto Domingo en 1870, Magdalena y su hermano José, con su mujer y sus hijos, fijaron su residencia en Madrid, y a este grupo familiar se incorporó Benito y su hermana Concha. De este modo se constituyó el hogar definitivo 
del novelista, que, como se ve, fue un hogar canario-americano. Don Benito tuvo, pues, a América en su casa. (1979: 10-11)

\section{El indiano de La loca de la casa}

No es nuevo nuestro interés en la figura del indiano en Galdós ${ }^{4}$; siempre nos ha atraído el tratamiento de estos personajes por parte del escritor, que en ningún caso es similar. Pensemos por ejemplo en la diferente actitud que se muestra ante el intachable y recto Agustín Caballero en Tormento, y ante el farfullero politicastro José María Manso, en El amigo Manso. El dinero es fuente básica en el ideal del indiano, no en vano lleva a cabo su trabajo para hacerse con un buen montón y regresar a España causando admiración a otros compatriotas que de nuevo se ensoñarán, en un ciclo repetitivo, con los logros de aquel. No es baladí el asunto del dinero de los inmigrantes pues supone, no solo un cambio social de clase para los protagonistas, sino una seria inyección de dinero para la debilitada economía española. Desde la construcción de empresas que favorecieron el tejido industrial hasta la restauración de patrimonio, como iglesias, cementerios, parques, etc., sin olvidar su fuerte aporte en el terreno educativo:

En relación con la influencia del dinero de los indianos en los lugares de procedencia se advierten dos periodos diferenciados. Aproximadamente hasta finales del siglo XIX, el emigrante que volvía con dinero invertía en terrenos, construía su chalet en el pueblo y vivía tranquilamente de sus rentas; algunos colaboraron con obras más o menos importantes en sus municipios, sin participar en la vida pública. A finales del siglo XIX y principios del XX la situación cambió radicalmente. El indiano rico pasó a formar parte de las clases activas del país: en vez de consumir sus rentas como próspero jubilado, las utilizó en la creación de nuevas empresas y nuevas fuentes de riqueza, de modo que ese capital aumentaba y contribuía al bienestar general. ${ }^{5}$

La versión novelesca de La loca de la casa, en la que centramos este estudio sobre el indiano, fue impresa en La Guirnalda en enero de 1893. En estos años finales del XIX observamos cómo se configura a través de la figura de José María Cruz

\footnotetext{
${ }^{4}$ V. Francisco J. Quevedo García, «Tres indianos en la novela galdosiana: Agustín Caballero, Teodoro Golfín y José María Manso», Actas del IV Congreso Internacional de Estudios Galdosianos, Las Palmas de Gran Canaria, Cabildo Insular de Gran Canaria, 1993, págs. 479-495; y Francisco J. Quevedo García, «El indiano o una particular deglución de América en la novelística de Benito Pérez Galdós», en Pasión caníbal. Documentos de cultura y de barbarie en América Latina, eds. Ángeles Mateo del Pino y Nieves Pascual Soler, Buenos Aires, Katatay, 2018, págs. 97-112.

${ }_{5}^{5}$ M. Ángeles Sallé Alonso (coord.), op .cit., pág. 160.
} 
- Pepet - la segunda posición que adopta el indiano comentada en la cita anterior. Aquí el indiano se encuadra en el proceso de actividad afín a los anhelos regeneracionistas como apunta Eva María Copeland:

The positive characterization of the indiano in this play can in part be due to the influence of regenerationism (the belief that Spain was decadent, exhausted, and needed regeneration) on Galdós at the time [...] This is the type of reform illustrated in La loca de la casa. Cruz, with his wealth and pragmatism, represents the pueblo, the working class that will renew the upper class. (2012: 236)

Pepet no llega a España con la decisión de vivir de las rentas en una cómoda y temprana jubilación. Pepet llega desbocado a Barcelona, a Santa Madrona, para seguir siendo lo que es: un empresario con iniciativa, un hombre hecho a sí mismo que repudia la pasividad en todos los órdenes - en la obra adquiere especial relevancia la que ejerce sobre el ámbito religioso místico contemplativo «Ya sabe usted que detesto a toda la caterva de frailes, clérigos y beatas, cualquiera que sea su marca, etiqueta o vitola...» ${ }^{6}$. Es verdad que en ese ánimo también se halla reivindicarse como el nuevo dueño de la casa donde servía su padre, lo que, obviamente, aunque se trate de un caso particular - con una meridiana vertiente amorosa - representa que la posibilidad de los cambios sociales a través del trabajo productivo son posibles en aquella España que se encarrila en el proceso transformador propiciado por la Revolución Industrial: «En mis sueños de hombre rico, que si el pobre sueña el rico más, he vislumbrado siempre una como rehabilitación gloriosa y triunfante de aquellas tristezas de mi niñez. Mi ilusión constante, mientras viví en América, fue poseer Santa Madrona, ser señor donde fui criado, casi igual a las bestias» (pág. 190).

En José María Cruz, convertido por obra y gracia de su nuevo alcance monetario en el señor Cruz, se aprecian dos actitudes recurrentes a lo largo de toda la obra: la egolatría y la idolatría al dinero, la religión que en su caso ha sustituido a la tradicional religión católica en España. Por otra parte, aunque relacionado con ello, es $L a$ loca de la casa un abierto escaparate de dos posiciones enfrentadas en cuanto a la religión se refiere: la defensora de una práctica ortodoxa del catolicismo, encarnada en la mayoría de los personajes, pero sobre todo Eulalia, la tía de Victoria y Gabriela — «iMi tía! (Riendo). No la saques de sus rezos, de su labor de gancho, de sus visitas a todas las monjas y frailes que hay en tres leguas a la redonda» (pág. 164) -, así como en la propia Victoria, que no se puede considerar beata como su tía, pero que

\footnotetext{
${ }^{6}$ Benito Pérez Galdós, La loca de la casa (Yolanda Arencibia, ed.), vol. 16 de la colección Arte, Naturaleza y Verdad, Las Palmas de Gran Canaria, Ediciones del Cabildo de Gran Canaria, 2009, pág. 189. A partir de ahora utilizaremos esta edición para todas las citas de La loca de la casa.
} 
sí manifiesta una posición muy clara de su adhesión católica. Es cierto que deja el convento, sí, pero para llevar a cabo un acto de sacrificio religioso para salvar a su familia casándose con el bruto indiano - «Virgen Santa, Madre amantísima, dame valor... y en este trance decisivo de mi sacrificio, no permitas que la fiera me desprecie» (págs. 243-244) - . Pepet se sitúa al margen de ese catolicismo combatiéndolo con despreciativas consideraciones - «Eso del monjío, envolver su rostro en la desairada toca, vestirse con tan feo traje, adoptar una vida de estúpidas ñoñerías, entre beatas asquerosas y frailes imbéciles» (pág. 219), y creando su propia religión basada en el culto al dinero, si por culto puede llamarse una obsesiva dedicación a sus negocios con el fin de que sean los más prósperos y que sus inversiones sean las más rentables. El dinero y su culto crean interesantes escenas:

\section{EULALIA}

Horrible, vamos, señor Cruz, no crea usted que aquí nos trastornamos oyendo hablar de metales más o menos viles...

\section{HUGUET}

Eso se deja para nosotros los adoradores del becerrito. Estas señoras, cristianas bien curtidas, conservan sus almas en vinagre, o sea en el desprecio de las riquezas [...].

\section{JAIME}

No: hay que distinguir.

\section{CRUZ}

Yo no distingo nada, y aseguro que el dinero es bueno. Tengo bastante sinceridad para declarar que me gusta..., que deseo poseerlo, y que no me dejo quitar a dos tirones el que he sabido hacer mío con mis brazos forzudos, con mi voluntad poderosa, con mi corta inteligencia. (págs. 181-182)

Las ególatras alusiones que a lo largo de la novela Pepet va reiterando en torno a su persona como única responsable de su fortuna muestra su lado más aversivo, que se corresponde con la altanería que muestra a la hora de hablar de cómo ha ganado su dinero, que ha arrancado violentamente de esa América que no le ha regalado nada, y sobre todo con su decisión tajante de no prestar ayuda pues él tampoco la obtuvo de nadie. La lucha por la supervivencia se plantea en formulación económica, Pepet ha logrado sobrevivir y cuando vuelve a España quiere seguir sobreviviendo implantando su ley del esfuerzo y una implacable autonomía personal que no entiende de socorros y prestaciones a nadie; el yo se impone sobre el resto - «Pepet, músculo y voluntad, rudeza primitiva y lealtad, esfuerzo inagotable, ausencia de todo sentimiento compasivo, máximo individualismo, sentido religioso del dinero y de la 
propiedad, alud que arrasa cuanto se interpone al paso de su yo» ${ }^{7}$. Huguet le solicita una contribución para las víctimas de un incendio en Barcelona a la que socorren los burgueses de la ciudad y Pepet le contesta: « $i$ Tonterías! Aquí no hay más víctima que yo. Soy mi propia víctima... y ya me he socorrido» (pág. 251). Los improperios que recibe Pepet por su tosco carácter y, en especial, por su implacabilidad en cuanto a su dinero se refiere son numerosísimos, estos ataques intensifican su identidad antisocial con continuas referencias a su salvajismo a través de las más diversas animalizaciones. Parece un pimpampum que recibe de todos lados sin que le haga mella: «bárbaro [...] el gorilla, porque moral y físicamente nos ha parecido una transición entre el bruto y el homo sapiens [...] Hombre de baja extracción, alma sórdida y cruel, facha innoble [...] bruto [...] animal» (págs. 166-167). Estos desprecios recibe Pepet solo en la presentación del personaje, luego se incrementarán notablemente cobrando relevancia en ello su condición de indiano: «este caribe» (pág. 246), «este californiano de mil demonios» (pág. 247), «ese don Judas de California». La propia consideración de indiano parece condenarlo a una degradación: «Es de esos que van cerriles a América, y luego vuelven cargados de dinero. La Providencia nos ofrece a cada instante estas ironías horribles» (pág. 166).

Todo gira en torno al dinero en La loca de la casa, es el Galeoto que une a Victoria y Pepet; por cierto, de forma muy poco romántica, a través de un contrato comercial pues así se concertó su matrimonio, fórmula que encaja en el contexto burgués de la obra. Desde su ubicación - Galdós se aleja de su Madrid habitual para situar la historia de La loca de la casa en Santa Madrona, una localidad cercana a Barcelona, la ciudad catalana en la vanguardia de la burguesía empresarial española - a los conflictos que van a conformar la acción dramática - quiebra de los Moncada, sacrificio de Victoria para salvar a su familia casándose con Cruz, redención o seudoredención de este-; el contexto burgués se prioriza hasta el punto de que en el estilo va a tener un peso específico el lenguaje comercial. Incluso Victoria, ya casada con el indiano, se va incorporando con dedicación a gusto a su nuevo papel de ayudante en la administración de los negocios de su marido y, claro, en su vocabulario caben ya los términos propios de las transacciones - «Grabada tengo aquí la última cantidad que escribí en el libro de la fábrica. ¡Tengo una memoria...! Era el saldo a tu favor de la cuenta del último trimestre... ¡Bonita cifra! Beneficio líquido: pesetas 27.433 con 78 céntimos» (pág. 318). Esto no obsta para que Victoria, en su afán redentor, le proponga a Pepet el cambio a una nueva visión económica y social que, como veremos, se imbrica en las ideas socialistas que adquieren apogeo en la época, pero también está ligado a su vertiente cristiana que aboga por la caridad, el reparto de bienes; en suma, por una actitud mucho menos ególatra que la que ha representado

\footnotetext{
${ }^{7}$ Joaquín Casalduero, Vida y obra de Galdós (1843-1920), Madrid, Gredos, 1974, pág. 111.
} 
el positivista monetarismo a ultranza de su marido: «Socialista..., así se dice... la idea de apoderarme de ti, invadiendo cautelosamente tu confianza, para repartir tus riquezas, dando lo que te sobra a los que nada tienen... para ordenar las cosas mejor de lo que están, nivelando ¿sabes?, nivelando...» (pág. 278).

Hemos hablado del proceso de redención que lleva a término Victoria con su indiano, aunque quizás con más propiedad deberíamos hablar de pseudoredención. Recordemos la advertencia de Ricardo Gullón para ver La loca de la casa como un texto complejo, pues los personajes se individualizan: «[...] la novela no contiene tan solo la fácil solución a un problema social, sino que los personajes, superando su carácter arquetípico, negándose a servir de esquemas para una demostración, revelan complejidad y humanas contradicciones, enriqueciendo y vitalizando el proyecto novelesco inicial» ${ }^{8}$. Tras la separación del matrimonio Cruz, José María y Victoria vuelven, igual que lo hiciera cuando concertaron el matrimonio, a sellar un nuevo acuerdo, pero ahora quien tiene la baza ganadora es la mujer, no tanto por el amor que le dispensa su cónyuge, que es bastante para su naturaleza ruda, sino porque Victoria espera un hijo suyo -«En La loca de la casa nos encontramos con una situación irónica en la cual la heroína ejerce el poder de una forma muy "masculina", aunque la base de su poder está en su capacidad biológicamente femenina de la maternidad» (2004: 197)-. El hijo es otro elemento que contribuye a caracterizar al burgués; supone la continuidad de su empresa, de sus firmas, de sus negocios, de su hacienda, y de su posición social, que ya no se va a contentar con permanecer en la clase media sino que aspira, nada menos, que a la aristocracia en un giro de ciento ochenta grados:

¡Un hijo, tener un hijo! Pues ¿para qué me he casado yo? ¿Por qué trabajo, por qué soy como soy... Don Juan (Cogiéndole por las solapas), no me contento con que Victoria me dé un hijo. Tiene que darme muchos, muchos; y a todos les criaré en el amor de la propiedad, en la religión del tuyo y mío, en el culto sagrado de la contabilidad, en el trabajo... y en todo lo demás que ella quiera.

\section{MONCADA}

Difícil me parece que tengas tantos... Uno quizás...

\section{CRUZ, furioso}

¡Pues no faltaba más...! Digo que nos reconciliaremos, y tendré muchos hijos, don Juan, aunque usted se oponga...

\footnotetext{
${ }^{8}$ Ricardo Gullón, Galdós, novelista moderno, Madrid, Gredos, 1973, pág. 117.
} 


\section{MONCADA}

Yo... como oponerme... no.

\section{CRUZ}

Y realizaré el sueño de mi vida, pese a quien pese. Victoria y yo seremos fundamento de una gallarda generación, y perpetuaré mi nombre, unido al de Moneada, y mis hijos serán condes, duques y marqueses, y vivirán con el esplendor que a su rango corresponde, y aumentarán las riquezas ganadas por su padre, y tendrán inmensa propiedad, tierras sin fin, granjas, montes, valles, provincias, casas, palacios, barrios, ciudades, y nuestra casa, nuestra firma como industriales, como comerciantes, como banqueros, como terratenientes, como especuladores, como agiotistas... será la primera de Barcelona, y de Cataluña, y de España, y del mundo entero. (págs. 309-310).

Por muy conocidas que sean, se hacen necesarias aquí las alusiones del escritor a la clase media como centro de su creación literaria -porque a la vez la considera núcleo del cambio socioeconómico y político de España- que lleva a cabo en sus «Observaciones sobre la novela contemporánea en España», publicado en 1870, y en «La sociedad presente como materia novelable», su discurso de recepción en la Real Academia Española en 1897. Si en el primer texto había apuntado en la diana sobre la obligación de la novela en dar cuenta de esa clase media, «la más olvidada por nuestros novelistas, es el gran modelo, la fuente inagotable» (1971: 323), ante los miembros de la Academia realiza un examen sociológico de esta clase media que encaja perfectamente con el indiano que sube de extracción social: «La llamada clase media, que no tiene aún existencia positiva, es tan sólo informe aglomeración de individuos procedentes de las categorías superior e inferior, el producto, digámoslo así, de la descomposición de ambas familias: de la plebeya, que sube; de la aristocrática, que baja» (1897: 18). Mientras que la marquesa de Malavella y sus dos hijos son muestra de ese descenso aristocrático, Pepet lo es, sin duda, de ese ascenso. La vía para lograrlo ha sido la del trabajo; el lugar elegido, la América mítica que le ofreció la oportunidad de conseguir la ansiada fortuna para convertirse en un indiano que se hizo señor donde antes había sido criado.

\section{Bibliografía}

Casalduero, Joaquín, Vida y obra de Galdós (1843-1920), Madrid, Gredos, 1974. Condé, Lisa Paulina, «El uso y el abuso del poder en La loca de la casa de Benito Pérez Galdós», en Galdós y la escritura de la modernidad. Actas del VII Congreso Internacional Galdosiano, de Yolanda Arencibia, María del Prado Escobar y Rosa 
María Quintana (eds.), Las Palmas de Gran Canaria, Cabildo de Gran Canaria, 2004, págs. 197-210.

Copeland, Eva María, «Empire, Nation, and the indiano in Galdós's Tormento and La loca de la casa», Hispanic Review, vol. 80, n. ${ }^{\circ}$ 2, 2012, págs. 221-242.

Del Río, Ángel, Estudios galdosianos. New York, Las Americas Publishing Company, 1969.

García Barrón, Carlos, «América en Galdós», Anales de Literatura Española, n. ${ }^{\circ}$ 5, 1986-1987, págs. 145-152.

Gullón, Ricardo, Galdós, novelista moderno, Madrid, Gredos, 1973.

Ferreras, José Ignacio,Introducción a una sociología de la novela española del siglo XIX. Madrid, Edicusa, 1973.

Morales Padrón, Francisco, Canarias y América, Las Palmas de Gran Canaria, Mancomunidad de Cabildos, Plan Cultural y Museo Canario, 1982.

Pérez Galdós, Benito, «La sociedad presente como materia novelable» (Discurso leído ante la Real Academia Española), en Discursos leídos ante la Real Academia Española, de Marcelino Menéndez y Pelayo, José María de Pereda y Benito Pérez Galdós, Madrid, Est. Tip. de la Viuda e Hijos de Tello, 1897, págs. 5-29.

Pérez Galdós, Benito, «Observaciones sobre la novela contemporánea en España», en Ideología y política en la novela española del siglo XIX, de Iris M. ${ }^{a}$ Zavala, Madrid, Anaya, 1971, págs. 317-331.

Pérez Galdós, Benito, El amigo Manso. Madrid, Alianza, 1983.

Pérez Galdós, La loca de la casa (Yolanda Arencibia, ed.), vol. 16 de la colección Arte, Naturaleza y Verdad, Las Palmas de Gran Canaria, Ediciones del Cabildo de Gran Canaria, 2009.

Pérez Vidal, José, Canarias en Galdós. Las Palmas de Gran Canaria, Cabildo Insular de Gran Canaria, 1979.

Quevedo García, Francisco J., «Tres indianos en la novela galdosiana: Agustín Caballero, Teodoro Golfín y José María Manso», en Actas del IV Congreso Internacional de Estudios Galdosianos, Las Palmas de Gran Canaria, Cabildo Insular de Gran Canaria, 1993.

Quevedo García, Francisco J., «El indiano o una particular deglución de América en la novelística de Benito Pérez Galdós», en Pasión caníbal. Documentos de cultura y de barbarie en América Latina, de Ángeles Mateo del Pino y Nieves Pascual Soler (eds.), Buenos Aires, Katatay, 2018.

Sallé Alonso, M. A Ángeles (coord), La Emigración Española en América: Historias y Lecciones para el Futuro, Madrid, Fundación Directa. Ministerio de Trabajo e Inmigración, 2009.

Sender, Ramón J., La aventura equinoccial de Ramón J. Sender, Madrid, Magisterio Español, 1976. 